\title{
STUDENTS' MASTERY OF ADJECTIVE CLAUSE: A CASE STUDY TOWARDS THE SECOND SEMESTER STUDENTS OF ENGLISH DEPARTMENT
}

\author{
Aisyah Al Baroroh ${ }^{1}$, Umi Hani ${ }^{2}$, \\ Universitas Pamulang ${ }^{1 \& 2}$ \\ dosen01054@unpam.ac.id ${ }^{1}$,dosen00620@unpam.ac.id ${ }^{2}$
}

\begin{abstract}
This study aims at analyzing the students' ability in answering grammar questions about adjective clauses. The method used to analyze the data is qualitative descriptive method. The result of the study showed how well students' capability of the second semester student of English department at Universitas Pamulang in dealing with grammar questions about adjective clauses. There were 26 random students from two different classes in the same semester who were included in this study. The study shows that the average of students score resulted them to be classifed to have Fair (got 60 to 69 score) category of adjective clause mastery by reaching $46 \%$ of the total percentage.
\end{abstract}

\section{Keywords: English Grammar, Adjective Clauses, Second Semester, English Department, Universitas Pamulang}

\section{INTRODUCTION}

Grammar is the study of sentence structure. According to Ur (2012), grammar is the technique used to put words together to make true sentences. As we all comprehend, each language has its own structure and grammar. This structure and grammar are also applied in English, especially in education field. As it is said by Azar (2007) to aid students find out the nature of language is the role of grammar. The nature of language itself contains predictable patterns which cause things that we speak, read, listen, and write become comprehensible. As she also stated that communicating meaning without grammar, would make people own only individual words or sounds, pictures, and body language. In teaching grammar, when students are asked to write, effective grammar instruction can help them to construct the sentences correctly. In many chances, students are required to make difficult sentences by using different types of sentences. In these type situations, comprehending how to make sentences with multiple clauses are extremely helpful. Students do not have to try to make such extremely complex sentences, however they should comprehend the concept of a dependent clause. A dependent clause is subsidiary in structure and in sense to the independent clause. Ultimately, the students have to spontaneously recognize all types of clauses and sentences they will possibly face. In addition, one of clauses in English grammar is adjective clause.

One of grammar areas that must be mastered by university level students is adjective clause. According to Swan (1998:15) Adjective is commonly used to explain things, people, events, and so on. Adjective is also used in linking nouns and pronouns. Its supreme typical place is before the noun or pronoun which it modifies. To sum, adjective modifies nouns or pronouns. Therefore adjective clauses are considered important for students to master as it was found out that there are a lot of students have problems in constructing complex sentences by using adjective clause. This becomes the main reason why this research needs to be conducted.

According to Parrott (2002), one of students' mistakes in constructing adjective clause is using double pronoun and unnecessary pronoun. In this case, the students do not know that another function of adjective clause is to replace subject or object in subordinating clause. They 
put double subject or object in adjective clause or they use wrong relative pronouns as subject or object in adjective clause. Another study from Thomson and Martinet (1986), indicates that students get problems in choosing relative pronouns, so they make the incorrect relative pronouns.

Based on the contents of course syllabus of English Grammar in English Department of Universitas Pamulang of second semester students, the tasks in adjective clause material are about learning and controlling independent clauses with one dependent clause correctly connected to the independent ones. In English literature Department, Grammar is learned from the first semester to the fourth semester. One of grammar areas that they should be studying in the second semester is the adjective clause. In the second semester, they have to study about adjective clause and how to use relative pronouns correctly. They should be able to join two sentences using adjective clause and how to use it. Because an adjective clause cannot stand alone, it does not express a complete thought. As a result, students must connect each adjective clause to a main clause to avoid writing a fragment. This study is aimed to be carried out to find out the mastery of adjective clause of university level students in the second semester. In this case, the writers are curious to know about analyzing of students' mastery on adjective clause with the study entitled "Students' Mastery of Adjective Clause: A Case Study towards the Second Semester Students of English Department"

\section{REVIEW OF LITERATURE}

A study by Andersen (2014) reported that students sometimes make error in writing complex sentence, group of words containing a subject and predicate and functioning as a member of complex or compound sentences. Generally, to make a complex sentence needs two kinds of clauses: main clause and subordinate clause. Main clause, consist of a subject and a predicate, can stand alone as sentence. Subordinate clause is an incomplete thought; a clause which is used to add more information to sentences. Subordinate clause begins with subordinating conjunctions or relative pronouns, which both play role in making the clause subordinate. One type of subordinate clauses is adjective clause. It is one of the most familiar types that have attracted the attention of researchers and educators because of its complex structures and seeming difficulty to language students.

\section{Underlying theories}

1. The Students' Mastery in General

Reviewed by Ramadhani in her research, mastery is the level or stage of learners in one subject in any case. In her writing she reviewed that mastery is capacity power doing or acting physically, mentally, legally, morally or financially. The mastery meant here is the achievement of the students after being taught for certain period of time. Mastery is higher than ability in level (Ramadhani, 2015).

$$
\text { Mastery }=>75 \% \text { even ability between } 65 \%-74 \%(\text { Ramadhani, 2015). }
$$

Still according to her writings, the term ability is the capability of the students to understand the materials given by the teacher and it can be seen from the result of the learning. Of course, the ability of each student to master the materials is not the same, although taught by the same teacher. It happens because their capability to comprehend the materials are different.

\section{Definition of an Adjective Clause}

Adjective clauses are dependent clauses. According to Keith and Elena, et cetera (2008:187), a group of words consists of a subject and a verb that modifies or describes a noun or a pronoun is called adjective clause. Sometimes they are called relative clauses as they frequently define and help to describe person.

An adjective clause usually comes immediately after the noun. It usually begins with a relative pronoun. Azar (2002: 267), defines adjective clause as dependent clause that modifies a noun. It describes, identifies, or gives further information about noun which is 
also called a relative clause. Oshima and Hogue (1999:212) identify different kinds of adjective clauses. One kind of adjective clauses is relative pronoun for person. There are who and whom. Relative pronoun "who" is used to explain person, the antecedent of relative clause. Huddleston and Pullum (2005:13) give an example about "who" relative pronoun:

"The secretary wrote to all the members who were absent from the meeting." They explain that the underlined relative clause modifies members and combines with it to form the head nominal. Then, regarding relative pronoun "whom", Broukal (2004:346) states that whom is very formal English. The use "whom" only in formal situation, such as when it is writing for a school and speaking in a speech.

3. Function of Adjective Clause

Artono (1987:79) says that adjective clause functioned like any adjective and this is used to modify a noun or pronoun. It is generally introduced by a relative pronoun or relative adverb, either of which expressed or implied. The relative pronoun and the relative adverb perform dual functions in any sentence in which either occurs. The relative pronoun stands for a noun expressed or clearly implied in a preceding clause, which is principal to the one introduced by the relative pronoun. The relative adverb has still more complex nature: it stands for a prepositional phrase containing relative pronoun as its principal word. In addition to their functions as pronoun and adverb, the relative pronoun and the relative adverb have the force of conjunctions in that they also join clauses.

4. Recognize an adjective clause

There are some types of adjective clauses. The types of adjective clause based on what the introductory words refer to Frank (1972:276), they are:

a. Introductory words referring to person "who, whom and whose"

Example:

- This is John, who always goes to the park on weekend

- The woman whom he loves left him

- A mother whose money was stolen is upset

b. Introductory words referring to a thing "which and that"

Example:

- There is the house which/that I used to live in

- The money for which/that he uses to buy car was left

c. Introductory words referring to time "when"

Example:

- $\quad$ The date, when I was born, was June 29th, 1983

d. Introductory words referring to place "where"

Example:

- This is the campus where I took my master degree

e. Introductory words referring to a reason "why"

Example:

- Please tell me why you leave him.

5. Reduction of Adjective Clause

Generally, there are four different techniques in which an adjective clause can be reduced. They are:

a. An ing' form and 'ed' is used as an alternative of a relative pronoun and an active verb either in present or past example:

- The woman who is teaching grammar is Lia. Reduced: The woman teaching grammar is Lia.

- The topic which is presented in that book is good. Reduced: The topic presented in that book is good

b. The subject pronoun is omitted and the 'to be' of verbs is omitted. 


\section{Example:}

- The girls which are pretty have some beautiful cars. Reduced: The pretty girls have some beautiful cars.

c. If there is no 'to be' of a verb in the adjective clause, sometimes it is possible to erase the subject pronoun and change the verb -ing.

Example:

- Children who attend this school had to wear uniform. Reduced: Children attending this school had to wear uniform.

d. If the adjective clause needs commas, commas should be placed in the adjective phrase, the subject pronoun and the 'to be'.

Example:

- Bandung, the capital city of West Java is a a right choice to culinary visit. Reduced: Bandung the capital city of West Java is a a right choice to culinary visit

\section{METHOD}

\section{Approach of the Study}

The qualitative approach is used in utilizing the process of data collection through surveys by distribution of research tools, analysis and data description. Furthermore, the descriptive qualitative methodology is applied. As Kothari (2004) says that the description of the state of affairs as what lives today as the main objective of descriptive research or study. At the same time, by doing a descriptive study we are able to analyze different types of aspects which can encourage people to act in certain way or generate people's preferences to like or dislike particular things.

\section{Data Source}

In this study, the writer will take from about 25 respondents as its data, consisting of second semester students of English Department in Pamulang University. Purpose of this study is to find out students' capability in comprehending adjective clauses. The approach that is used in this study is the analysis of students' ability through qualitative descriptive method. In this study, writers will analyze respondents' answers related to questions contained in the questionnaire given.

\section{Data Collection}

Based on Mile and Huberman, in Sugiyono, (2009: 246), there are certain argumentations about the activities in qualitative data analysis which are carried out interactively and simultanously until the analysis is finished so that the data is saturated. Such models are usually known as Interactive Models. According to the experts, there are three steps in qualitative data processing: reduction of data, display of data and drawing of conclusion.

\section{Method of Data Analysis}

At this phase, the qualitative data analysis is implemented out before going into the field, during the process at the field and after completion in the field. As It is supported by Nasution, in Sugiyono (2009), the analysis had begun since the problem's design and explanation process, before getting into the field, and it is continued until the process of results of research writing ended. Until the theory is "grounded" (if possible), data analysis becomes a principle for further research. But in qualitative research, data analysis is more centered during the field process along with data collection.

\section{FINDINGS AND DISCUSSION}

To get the data, there were 26 random students taken from two different classes in the same semester tested. The test consists of 10 questions of combining sentences, 10 questions of blank filling, and 5 questions of identifying correct or incorrect sentences. There was also a questionnaire attached so they needed to answer that after taking the test. In analyzing the data, The writer separates the points into average of total score by using the median calculation to 
specify the students into certain categories and per type of questions score to deepen the analysis.

To make it easier to be discussed, in this study, the students were classified into several categories of mastery; Very Good, Good, Fair, Poor, and Very Poor. Students are classified into Very Good when their score reach 80 - 100. They are classified as Good when they get 70 - 79. They get Fair category when they only reach 60-69. For those who get 50-69 are categorized as Poor. The lowest category is Very Poor which is labeled for those who get below than 50 .

Once computing the data, it can be established that the students' mastery in comprehending grammar material about adjective clause is categorized as Fair. This result is shown by total 11 students out of 26 who got 60,0 to 66,7 score in the test. The data is categorized as it is pictured at the below chart.

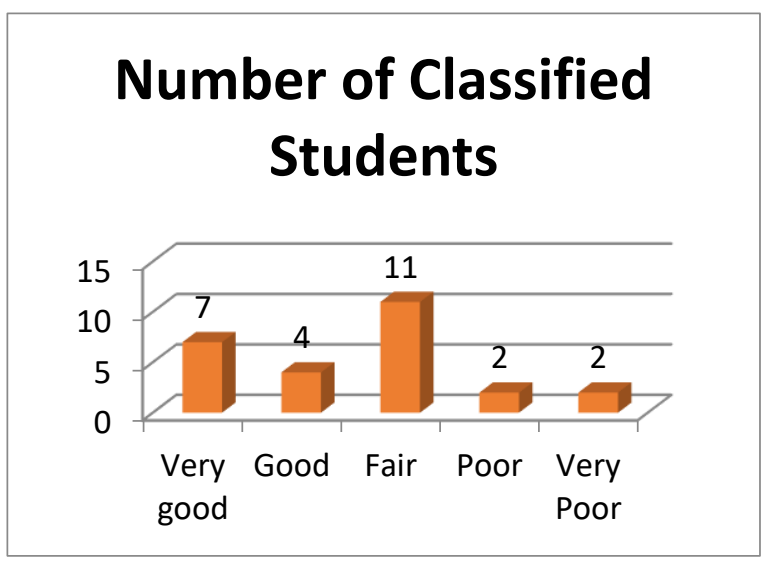

Figure 1

\section{Students' Classification}

Percentage

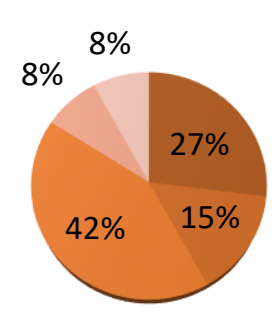

Very Good (80-

100)

Good (70-79)

Fair (61-69)

Poor (50-59)

Figure 2

Based on the above chart, the highest number of students was categorized as Fair with 11 out of 26 students. They were specified so due to the average score that they got between 61 to 69 and this category reached $42 \%$ of the total participants' average score. The second highest category was Very Good with 7 participants got 80 to100 and reached $27 \%$ of the score. This range shows that there are quite many students master the material. The third highest category was Good with 4 students got 70 to 79 with $15 \%$ percentage. As for the least two categories were Poor and Very Poor. Those two categories share the same number of students and percentage with 2 students each and $8 \%$ percentage. These numbers then needed the writers to have a deeper analysis.

Narrowing down to per type questions, the writers made the questions by referring to Azar (2002). The writer then classified the students mastery through types of questions that they did in the test and found out that many students had through quite high difficulty in the first type of question, that was combining sentences; questions Type 1. This type of questions was considered to be the most difficult questions. This type of questions required students to combine two independent clauses into one sentence by using subordinate conjunction of adjective clause. There were 9 students who got 30, which was the lowest score in this type of questions. There was 1 student got 40 and there also were quite high number of students to get 60,7 students. The calculation of those in very poor to fair qualification reached more than half of the test participants. It means that many of the students found it difficult to combine two sentences and complete it with adjective clauses.

By seeing the result, many of the students confused about noun or pronoun that the adjective clause should modify. One another problem was also to decide which sentence should be the main sentence or the independent clause and which sentence should be the adjective clause or the dependent clause. By referring to the questionnaire, this problem occurred mainly because some the students failed to comprehend fully about the types of sentences so they could not distinguish correct sentences to be modified. Some of the students also had some problems in deciding appropriate subordinate conjunctions that agree with the word that it modified. This kind of problem also correlated with problems that were faced by some of the students in another type of questions. One student even said that he had trouble formulating the sentence 
structure. So, it can be concluded that students' mastery in those mentioned aspects were low. The number is presented in Figure 3.

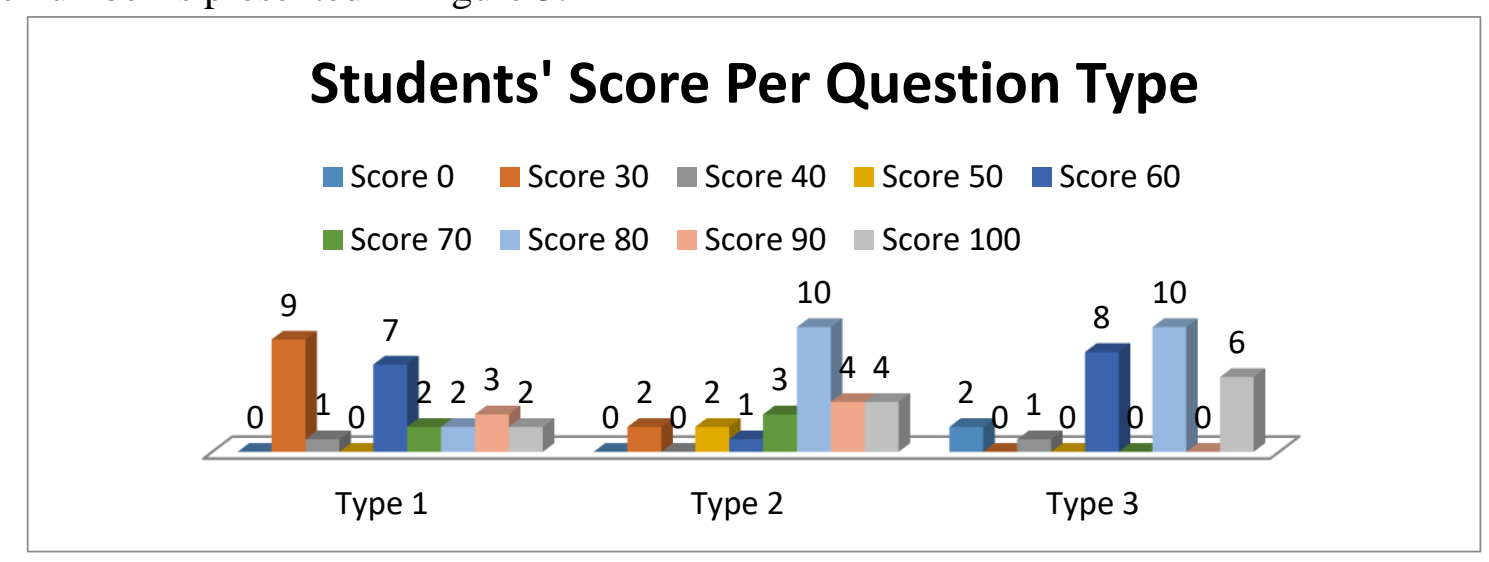

Figure 3

As it seen on the above chart, the questions that were considered to have average level of difficulty were Type 2 questions, completing blanks with appropriate subordinate conjunctions. There were 18 total students who could be classified into very good category. It means that more than half of the tested students could determine correct subordinate conjunctions for the preceded noun or pronoun. Based on the questionnaire, many of them found it difficult to distinguish the use of each conjunction. Meanwhile, some other students had quite difficult problem in specifying subject or object of the main clause which should be modified. After analyzing the case, the writer agrees to one conclusion that students' mastery in those mention aspects was average.

The last type of questions, Type 3, was about identifying correct or incorrect sentences with adjective clause. The result of this study about the students' mastery in aspects which were scored in this type was really interesting. There were 6 students who got 100 as their scores in this type of questions. This was the highest total number of students among the questions types with excellent score. It shows that some students could analyze and identify the adjective clause sentences really carefully. However, higher total number of students was shown to get 60 as their score. There were also 2 students who completely failed to identify the sentences. These two students got 0 in doing this type of questions. These findings indicated that more students had through difficulty in identifying whether the sentence structure of adjective clause was constructed correctly or not. Some other students may just follow their intuition to decide that, depending on their luck. By these findings, the writer indicates that the students' mastery in this type of questions was also average.

\section{CONCLUSIONS}

Based on the findings and discussion which were elaborated previously, it can be concluded that the Fair classification of the median score of the tested students were caused by the average mastery of certain aspects of adjective clause in each type of the questions. There were $42 \%$ (11 students) got 60 to 69 as their final score of the test. Many students were unable to create and identify sentences by using adjective clause correctly. Some of them were also still confused on specifying certain subordinate conjunctions as well as their functions on each sentence. Some other students could not identify certain subject or object in a sentence to put the adjective clause at the correct place. The worst case was there was also one student that did not understand the sentence structure and even did not know the differences between dependent and independent clause which is actually the basic comprehension to master this material. Those were the reasons which formulated the result of this study. This should be note for teachers or lecturers who teach this topic, to make sure that the students understand basic knowledge in formulationg the sentence or else the students will find it difficult to use adjective clause in their sentence.

\section{REFERENCES}


Azar, Betty Schrampfer. (2002). Understanding and Using English Grammar (4thEd). London: Longman.

Beverly, A. H. (2007). The Role of Grammar in Improving Student's Writing. Retrieved October 1, 2007, from http://www.sadlieroxford.com/docs/language/paper_chin.cfm

Brown, J. D. (2003). Research Methods for Applied Linguistics. In A. Davies \& C. Elder (Eds.), The Handbook of Applied Linguistics (476-500). Oxford, UK: Blackwell. Kothari, C.R. (2004). Research Methodology; Methods and Techniques. New Delhi: New Age International (P) Limited, Publishers

Macky, Alison and Gass, Susan M. (2005). Second Language Research: Methodology and Design. New Jersey: Lawrence Erlbaum Associates, Inc., Publishers

Parrott, Martin. (2000). Grammar for English Language Teachers. Cambridge: Cambridge Press University

Sarah Andersen, Sentence Types and Function, San Jose State University Writing Center, the International Journal of English Linguistics; Vol. 4, No. 4; 2014 ISSN 1923-869X E-ISSN 1923-8703

Scollon, R. (2001). Action and Text: Toward an Integrated Understanding of The Place of Text in Social (Inter)Action. In R. Wodak \& M. Meyer (Eds.), Methods in Critical Discourse Analysis (Pp. 139-183). London: Sage.

Swan, Michael. (2002). Practical English Usage. Oxford: Oxford University Press,

Tetnowski, J., \& Damico, J. (2001). A Demonstration of The Advantages of Qualitative Methodologies in Stuttering Research. Journal of Fluency Disorders, 26, 17-42.

Thompson, R., \& Jackson, S. (1998). Ethical Dimensions of Child Memory Research.

Thomson, A. J and A. V. Martinet. (1986). A Practical English Grammar. Oxford: Oxford University Press

Ur, Penny (2012). A Course in Language Teaching. UK: Cambridge University Press 